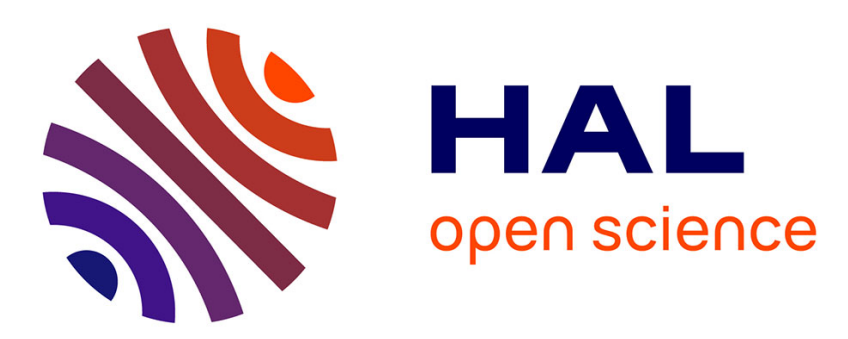

\title{
Induction of Magnetic Accommodation Processes in Polycrystalline Yttrium Iron Garnet
}

C. Torres, C. de Francisco, Lionel Torres, R. de Miguel, P. Hernández, J.

Iñiguez

\section{- To cite this version:}

C. Torres, C. de Francisco, Lionel Torres, R. de Miguel, P. Hernández, et al.. Induction of Magnetic Accommodation Processes in Polycrystalline Yttrium Iron Garnet. Journal de Physique IV Proceedings, 1997, 07 (C1), pp.C1-289-C1-290. 10.1051/jp4:19971114 . jpa-00254754

\section{HAL Id: jpa-00254754 https://hal.science/jpa-00254754}

Submitted on 1 Jan 1997

HAL is a multi-disciplinary open access archive for the deposit and dissemination of scientific research documents, whether they are published or not. The documents may come from teaching and research institutions in France or abroad, or from public or private research centers.
L'archive ouverte pluridisciplinaire HAL, est destinée au dépôt et à la diffusion de documents scientifiques de niveau recherche, publiés ou non, émanant des établissements d'enseignement et de recherche français ou étrangers, des laboratoires publics ou privés. 


\title{
Induction of Magnetic Accommodation Processes in Polycrystalline Yttrium Iron Garnet
}

\author{
C. Torres, C. de Francisco, L. Torres*, R. de Miguel, P. Hernández and J. Iñiguez* \\ Departamento Electricidad y Electrónica, Facultad de Ciencias, Universidad de Valladolid, \\ 47071 Valladolid, Spain \\ * Departamento Física Aplicada, Facultad de Física, Universidad de Salamanca, 37071 Salamanca, \\ Spain
}

\begin{abstract}
Magnetic disaccommodation phenomena are studied in YIG polycrystalline samples. The compounds were prepared by a ceramic technique and sintered at temperatures ranging from $1350^{\circ} \mathrm{C}$ to $1450^{\circ} \mathrm{C}$ in air and $\mathrm{CO}_{2}$ atmospheres. The results are presented as isochronal spectra of the relative time variation of the initial magnetic permeability after specimen demagnetization. For samples sintered in air atmosphere, it can be observed a clear positive relaxation peak around $125 \mathrm{~K}$. When the sintering temperature is increased, the amplitude of this peak decreases slightly and a new process appears at higher temperatures (around $180 \mathrm{~K}$ ). On the contrary, a drastic change is produced when samples are resintered in $\mathrm{CO}_{2}$ atmosphere. In this case, relaxation spectra exhibit negative peaks (accommodation processes) around $115 \mathrm{~K}$. Also, the relaxation features of these processes seem to be influenced by sintering temperature. Some reasonable speculations about the mechanism responsible for this behaviour are pointed out.
\end{abstract}

\section{INTRODUCTION}

In the last years our group has reported several works dealing with magnetic disaccommodation (MDA) measurements in polycrystalline YIG depending on sintering atmosphere [1] and temperature [2]. We have also observed that magnetic accommodation (MA) processes appear in stoichiometric YIG samples sintered in atmospheres with low oxidation pressures $\left(\mathrm{P}\left(\mathrm{O}_{2}\right)<10^{-2}\right)$ [1]. In this paper we show how it is possible to induce accommodation processes in YIG samples sintered in air by a resintering in $\mathrm{CO}_{2}$ atmosphere. Comparison between MDA and MA spectra in these series of samples before and after the resintering in $\mathrm{CO}_{2}$ provides very interesting information for the understanding of magnetic accommodation processes.

\section{EXPERIMENTAL PROCEDURE}

For our purpose, a series of YIG polycrystalline samples has been prepared from stoichiometrically mixed high-purity $\mathrm{Fe}_{2} \mathrm{O}_{3}$ and $\mathrm{Y}_{2} \mathrm{O}_{3}$ powders. The mixtures were ball milled for several hours in an agate mortar, pressed in a cylindrical die and sintered for 8 hours in air at temperatures ranging from $1350^{\circ} \mathrm{C}$ to $1450^{\circ} \mathrm{C}$ according to the phase diagrams of the Y-Fe-O system [3]. Finally, vacancy annealing was avoided by rapid quenching in an air stream. Each sample was resintered at the same temperatures but now in $\mathrm{CO}_{2}$ atmosphere. $\mathrm{X}$-ray powder diffraction patterns of these samples showed that single phase YIG was obtained at each sintering temperature.

Magnetic aftereffect measurements have been carried out with a computer aided system based on an automatic LCR bridge [4]. During the measuring process, the time variation of the reversible magnetic permeability after sample demagnetization is recorded at different rate windows with scanning temperature. The measuring signal is a weak $\mathrm{lkHz}$ ac field, whereas specimen demagnetization is achieved by means of a linearly decreasing $100 \mathrm{~Hz}$ signal, with amplitude higher than coercitive field.

\section{3, EXPERIMENTAL RESULTS}

Figure 1 displays the isochronal spectra for YIG samples sintered in air at different temperatures, whereas the spectra for the same samples after resintering in $\mathrm{CO}_{2}$ are shown in figure 2. A first inspection of both spectra reveais that a profound change takes place in the magnetic relaxation processes of our samples after resintering. For the samples fired in air we can observe the presence of a relaxation process around $125 \mathrm{~K}$ which amplitude decreases with rising sintering temperature. When this temperature is higher than $1415^{\circ} \mathrm{C}$ a new process appears at $180 \mathrm{~K}$. These two phenomena exhibit the characteristics of thermally activated processes with activation energies close to $0.34 \mathrm{eV}$ and $0.4 \mathrm{eV}$, respectively. When the samples are 
resintered in $\mathrm{CO}_{2}$, the spectra change drastically which means that the relaxation features of these materials depend strongly on the sintering conditions and especially on the partial oxygen pressure. It can be seen in figure 2 how now a magnetic accommodation process is observed at $115 \mathrm{~K}$. At the same time a positive peak appears at temperatures immediately higher, around $130 \mathrm{~K}$. Finally, it is noteworthy that a new process takes place at $180 \mathrm{~K}$ when the sample is prepared at $1450^{\circ} \mathrm{C}$ as it happens in air atmosphere. Furthermore, we can note that in this last case a new negative peak seems to appear below the lowest temperature accesible by our experimental device $(80 \mathrm{~K})$.

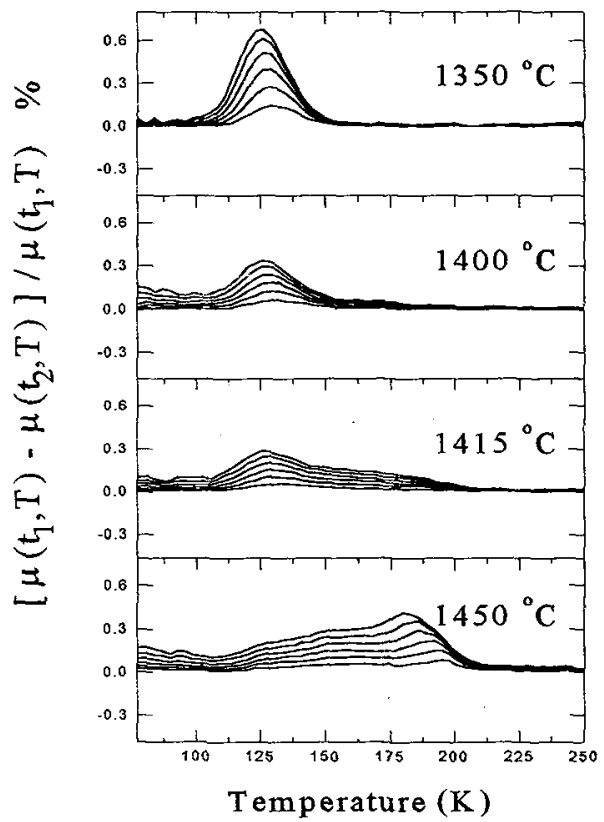

Figure 1: Isochronal relaxation spectra for YIG samples sintered in air at different temperatures $\left(t_{1}=2 \mathrm{~s}\right.$ and $t_{2}=4$, $8,16,32,64$ and $128 \mathrm{~s}$, curves from bottom to top).

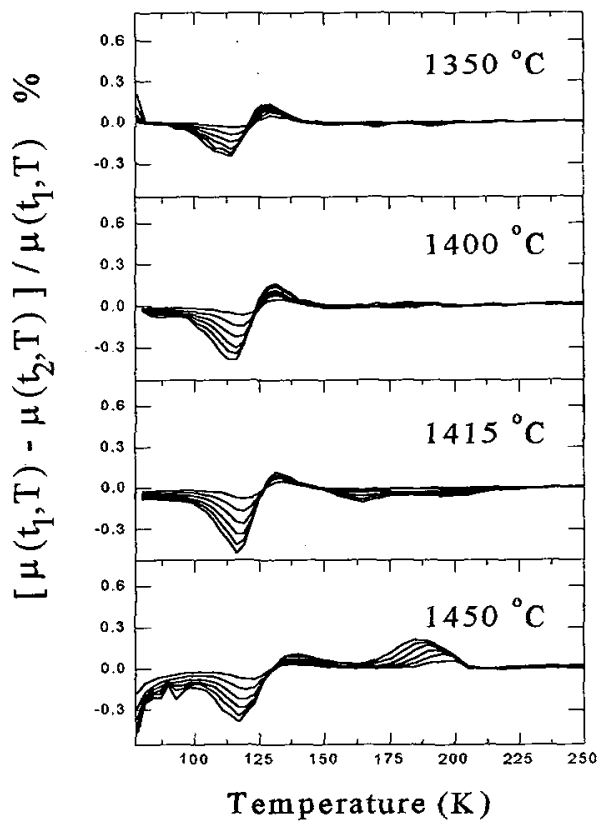

Figure 2: Isochronal relaxation spectra for YIG samples sintered in $\mathrm{CO}_{2}$ at different temperatures $\left(t_{1}=2 \mathrm{~s}\right.$ and $t_{2}=4$, $8,16,32,64$ and $128 \mathrm{~s}$, curves from bottom to top).

\section{DISCUSSION}

Keeping in mind the sintering conditions [4] it might be expected an oxygen deficiency in the crystal which promotes the existence of $\mathrm{Fe}^{2+}$ ions in octahedral positions. Thus, the process at $125 \mathrm{~K}$ in figure 1 is attributed to an electronic orientational process by means of point defects and the variation of its amplitude to the competition between the presence of ferrous ions and point defects when the sintering temperature is increased [2]. The thermally activated process at $180 \mathrm{~K}$, which appears when the sintering temperature is above $1415^{\circ} \mathrm{C}$, could be explained by the electron transfer between $\mathrm{Fe}^{2+}$ and $\mathrm{Fe}^{3+}$ ions in octahedral sites, which creates a local order responsible for incuced anisotropy and a domain-wall relaxation [1]. When the samples are resintered under low partial oxygen pressures, accommodation processes, that is, an increase in the initial permeability of the sample, are induced as we can see in figure 2 . These phenomena could be related with the appearance of some amounts of defects or diffusants inside the material [5]. These diffusants are responsible for a diffusion magnetic aftereffect which can be observed when the inverse of its relaxation time is smaller than the measurement frequency but both have the same order of magnitude. This is our case for low temperatures and $1 \mathrm{kHz}$ measuring frequency [5]. Therefore, the induction of magnetic accommodation processes could be due to an increase of diffusants or defects inside the material and of the associated diffusion relaxation when the samples are sintered under low partial oxygen pressures. Further researchs are required to verify this hypothesis.

\section{References}

[1] Torres L., de Francisco C., Muñoz J.M., Zazo M., Iñiguez J.I., J. Appl. Phys. 73 (10) (1993) 6301-6303

[2]:Torres L., Zazo M., Iñiguez J.I, de Francisco C., Muñoz J.M., IEEE Trans. Mag. 30 (6) (1994) 4903-4905

[3] Van Hook H.J., J. Am. Cer. Soc. 45 (4) (1962) 162-165

[4] de Francisco C., Iñiguez J.I., Muñoz.J.M., Ayala J., IEEE. Trans. Mag. 23 (2) (1987) 1866-1868

[5] Merceron T., Guyot M., Cagan V., Phys. Lett. 95A(7) (1983) 388-390. 